\title{
Increasing fatigue performance in AHSS thick sheet by surface treatments
}

\author{
Sergi Parareda ${ }^{1, *}$, Antoni Lara ${ }^{1}$, Henrik Sieurin ${ }^{2}$, Héber D'Armas ${ }^{1}$, Daniel Casellas ${ }^{1,3}$ \\ ${ }^{1}$ Fundació CTM Centre Tecnològic, Metallic and Ceramic Materials Department, 08243 Manresa, Spain \\ ${ }^{2}$ SCANIA AB, Materials Technology Department SE-151 87 Södertälje, Sweden. \\ ${ }^{3}$ Luleå University of Technology, Division of Mechanics of Solid Materials, 97187 Luleå, Sweden
}

\begin{abstract}
Advanced High Strength Steels (AHSS) have been widely applied in the automotive industry as an affordable solution for car lightweighting, mainly in parts subjected to crash requirements. Heavy duty vehicle (HDV) can also benefit from the expertise learned in cars, but parts must be designed considering fatigue resistance, especially on trimmed areas, and stiffness. Mechanical surface treatments, as blasting or shot peening, help increasing fatigue life of AHSS in trimmed areas and will allow weight reduction in HDV through gauge downsizing. The expected decrease in stiffness through thickness reduction can be improved by design changes. However, scarce information about the effect of mechanical surface treatments on AHSS are available. Thus, the aim of this work is to evaluate the increment in fatigue life of two different steel grades (350 MPa, and 500MPa of yield strength) in thick sheet by means of mechanical surface treatment - sandblasting. High Cycle Fatigue [HCF] tests were conducted at alternating load [R=-1]. Residual stresses were measured by an X-ray tensometry prior fatigue tests. Also the surface roughness [Rz] and form is measured using an optical non-contact $3 \mathrm{D}$ microscope. On the other hand, the fracture surfaces of the test specimens were observed via scanning electron microscope (SEM) in order to determine the crack initiation points. The evaluation of fatigue life in terms of SN curves is also discussed, analysing how the sandblasting process modifies the surface roughness and introduce compressive residual stresses on the external layer of the material. Both phenomena enhance the fatigue strength of the evaluated steel grades.
\end{abstract}

Keywords. High-cycle fatigue, thick sheet, sandblasting, HSS, AHSS, HSLA steel, residual stresses, Xray analysis.

\section{Introduction}

In the past years high strength steels and lightweight design have gained wide popularity to improve crashworthiness and reduce weight on passenger cars. Mainly efforts have been concentrated in the lightweight of the body in white (BiW) to achieve the GHG reduction targets. Passenger cars accounted for about $60 \%$ of global emissions in road transport in 2012 and it is expected to decrease to $45 \%$ by 2030 . On the other hand, heavy duty vehicles (HDV) accounted for about $30 \%$ of the overall GHG emissions at 2012 and it is expected to increase beyond $40 \%$ at 2030 [1]. In this context, $\mathrm{CO}_{2}$ standards, green taxation and the increasing alternatives in materials and forming processes for lightweighting are helping to reduce the global emissions for cars but emissions for trucks and buses are far to be decreased. Since the expected increase of HDV emissions is important enough to not be ignored, weight reduction in the truck and bus sector is the indicated way to make it cleaner. Although, the application of AHSS is less utilized in trucks and buses, there is a great weight reduction potential in exchanging traditional steel grades with AHSS also in HDV. Multiple key aspects such as lower energy (fuel) consumption, payload increase and material resource savings are directly related with a more efficient use of resources. A simple example is given by a supposed case in which if a $10 \%$ higher stress can be allowed by a material upgrading, the sheet thickness could be reduced by $5 \%$. Gauge downsizing is straight related with payload increase for weight dimensioned transport, thus in this case payload is increased by a $5 \%$ which means an improvement in freight transport and reduction of GHG emissions.

Owing to multiple loading situations during service, HDV parts have to satisfy high mechanical demands. The elastic behaviour and crashworthiness of the truck are satisfied with a high yield strength (YS) and high ultimate strength (UTS) respectively. Truck stability solicitation is accomplished by an appropriate design with a utilization of complex shapes to get the desired stiffness. On the other side, fatigue strength is a crucial property to satisfy. Since many parts are exposed to high cycle fatigue $\mathrm{Al}$ alloys are not a material choice due to its limited fatigue resistance. Accordingly, advanced high strength steels (AHSS) are the suitable material family candidate to achieve high weight reduction in

* Corresponding author: sergi.parareda@ctm.com.es 
HDV while improving part durability at affordable cost and environmental impact.

Fatigue behaviour is influenced by factors as steel strength, surface conditions, presence of non-metallic inclusions, welding defects, mean stress, residual stress, plate thickness, temperature, corrosion, number of cycles or applied stresses. Fatigue failures are often triggered by surface defects that can easily be generated during forming process. Several authors have studied the effect of cutting effect on fatigue features for carbon and microalloyed steels $[2,3]$.

a

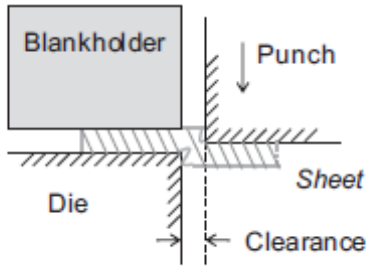

b

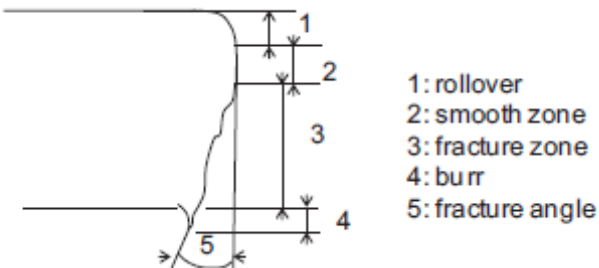

Fig. 1. (a) Illustration of trimming process and definition of cutting clearance. (b) Characteristics regions generated at the cut edge in mechanical cutting.

In this sense, the shearing process used in the automotive industry produce surface irregularities at the cut edge strongly affected by material type, material thickness, condition of cutting edges (sharp/worn), blankholder force, geometry of the cut and clearance (i.e. distance between punch and die). As a result of trimming process a typical cut edge shape can be observed on both the parent material and the cut-off. Five characteristics regions can be identified on the cut edge: rollover, smooth zone, fracture zone, burr and fracture angle which act as preferential sites to crack nucleation [4].

Infinite life design criterion based on SN or Wöhler curves is usually used to study the effect of cut edge on fatigue strength [5]. The associated fatigue life phenomenon is the crack nucleation, thus a way to enhance the fatigue strength is to delay the crack initiation. There are several factors that influence the crack initiation life: Surface roughness $(\mathrm{Rz})$, surface defects, surface treatments, residual stresses at the surface and notch effect $\left(\mathrm{K}_{\mathrm{t}}\right)$. Subsequent operations such as shot blasting or shot penning are suitable to modify and improve several of these factors $[6,7]$.

Shearing process is used in HDV industry due to the higher production rates that can be achieved and a fast cost amortization of the mechanical tools. Moreover, sandblasting operation is used as a pretreatment of trimmed parts to clean and smooth the surface before painting. Thus, keeping in mind the necessity to reduce the GHG emissions of HDV sector, the mechanical solicitations on chassis parts and the forming processes used, the present work aims at evaluating the effect of surface treatment as sandblasting on fatigue performance in AHSS. To achieve this objective, two different hot rolled HSLA steel grades with and without sandblasting process have been analyzed by constant stress amplitude alternate bending test. Materials with cut edge have been as reference in this study. Compressive residual stresses measurements have been carried out by X-ray tensometry [8] prior fatigue test. Besides, edge features have been analyzed by topographical $3 \mathrm{D}$ analysis.

\section{Experimental procedure}

Two hot rolled HSLA steel sheets of a thickness of $3 \mathrm{~mm}$ studied had a nominal YS of $350 \mathrm{MPa}$ and $500 \mathrm{MPa}$ respectively. Chemical composition and sheet thickness of the studied steels are listed in Table 1.

Table 1. Chemical composition (in wt $\%$ ) and sheet thickness of studied steels.

\begin{tabular}{|c|c|c|}
\hline Steel grade & $\mathbf{3 5 0}-\mathbf{3 m m}$ & $\mathbf{5 0 0}-\mathbf{3} \mathbf{m m}$ \\
\hline$\% \mathrm{C}$ & 0.067 & 0.0738 \\
\hline$\% \mathrm{Si}$ & 0.0167 & 0.0225 \\
\hline$\% \mathrm{Mn}$ & 0.587 & 0.798 \\
\hline$\% \mathrm{P}$ & 0.0061 & 0.0069 \\
\hline$\% \mathrm{~S}$ & $<0.0010$ & $<0.0010$ \\
\hline$\% \mathrm{Cr}$ & 0.0266 & 0.0361 \\
\hline$\% \mathrm{Mo}$ & $<0.0050$ & $<0.0050$ \\
\hline$\% \mathrm{Ni}$ & 0.0306 & 0.0339 \\
\hline$\% \mathrm{Al}$ & 0.0430 & 0.0429 \\
\hline$\% \mathrm{Nb}$ & 0.0243 & 0.0336 \\
\hline
\end{tabular}

The delivered 350 steel grade shows a homogeneous distribution of pearlite in a fine ferritic matrix (Fig. 2). 500 steel grade also shows a homogeneous distribution of pearlite in a ferritic matrix (Fig. 3), in this case much finer than the 350 grade. Fig 4 shows an oxide scale on the surface of both materials probably from steelmaking process.

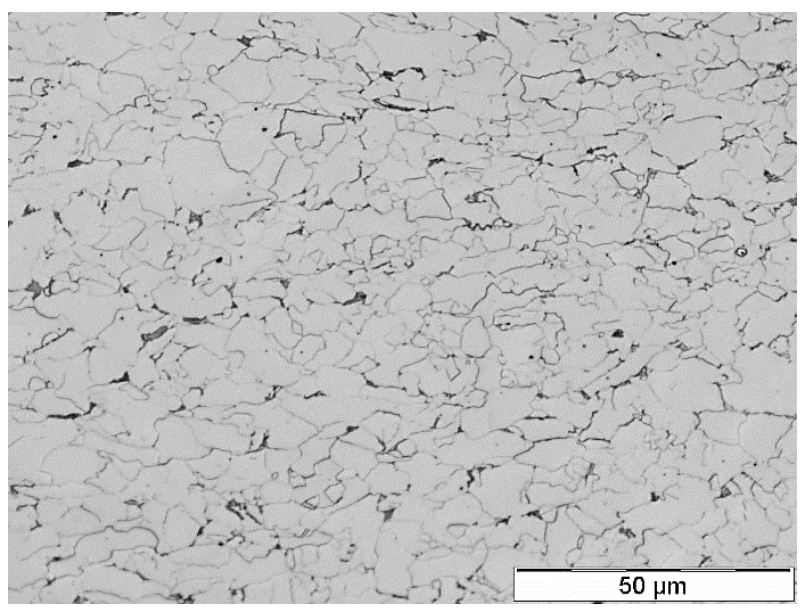

Fig. 2. Microstructure of 350 steel grade, ferrite-pearlite microstructure. 


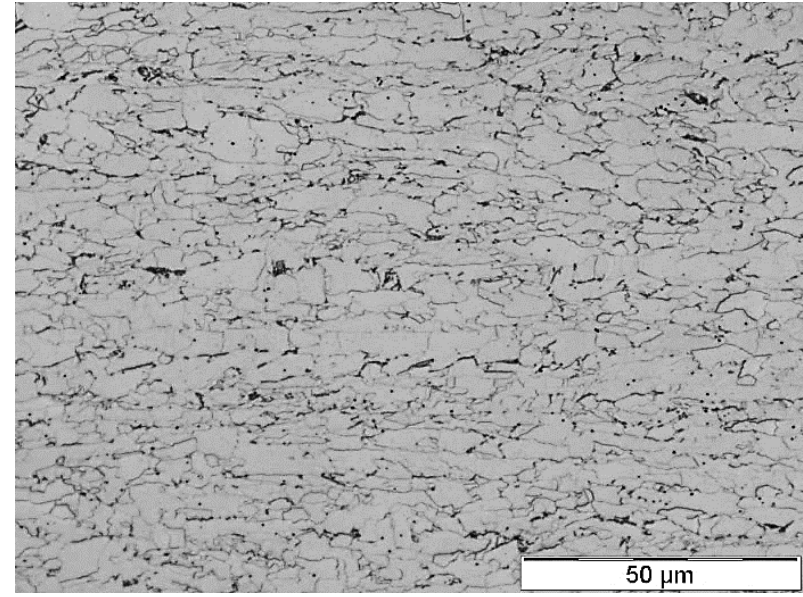

Fig. 3. Microstructure of 500 steel grade, finer ferrite-pearlite microstructure.

In order to evaluate the influence of the trimming process on the mechanical properties of the steel sheet, the calibrated zone of fatigue specimens (Fig. 6) was cut using a cutting clearance of $10 \%$ of the sheet thickness and a punch with sharp edges (radius close to $0 \mathrm{~mm}$ ). Shearing process conditions (i.e. clearance and punch radius) are defined according to the cutting conditions employed in the automotive industry.

Specimens were manually blasted after trimming using glass microspheres of 40 to $95 \mu \mathrm{m}$ of diameter as abrasive media and compressed air pressure of 6 bar. The distance between the workpiece and the nozzle was set at $20 \mathrm{~mm}$. The blasting direction was always perpendicular to the surface.

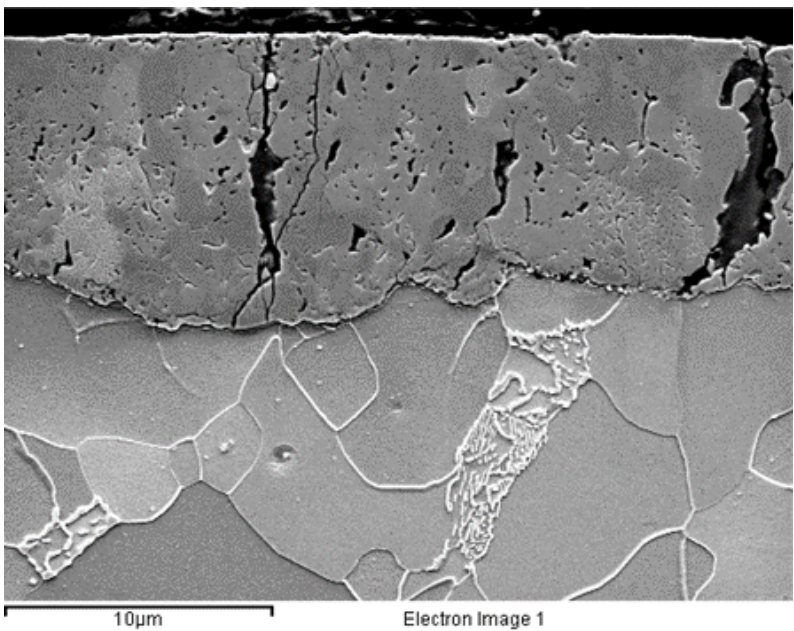

Fig. 4. Oxide scale in the 350 steel grade. It should be noted that the scale cracks do not penetrate the substrate.

Thus, two edge conditions are defined:

- Group 1 (G1): Trimmed edge

- Group 2 (G2): Trimmed edge and subsequent sandblasting operation

The edge quality resulting from each condition was evaluated by different techniques: (a) cross section inspection by optical microscopy (Fig. 5) (b) edge roughness (Rz) by, inspecting optical non-contact 3D microscope. Specimens cut in cross-section were etched with Nital at $2 \%$ to analyse the shear zone close to the edge. Compressive residual stresses were measured by the X-ray diffraction (XRD) technique at the surface of the calibrated zone after trimming and sandblasting processes. The area for the measurements of residual stress was $2 \mathrm{~mm}$ in diameter.

a
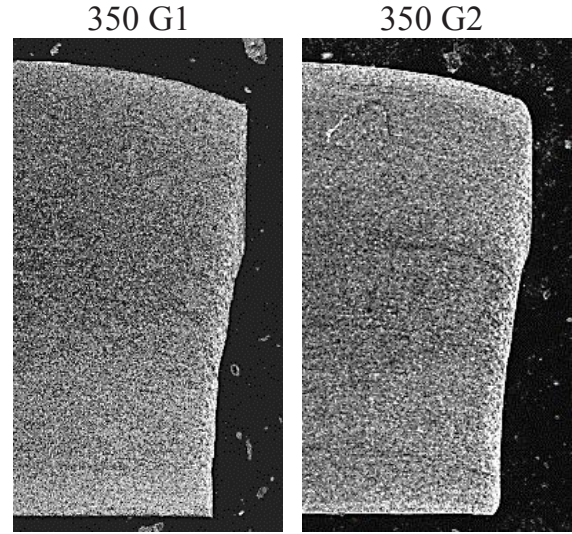

$1000 \mu \mathrm{m}$

b
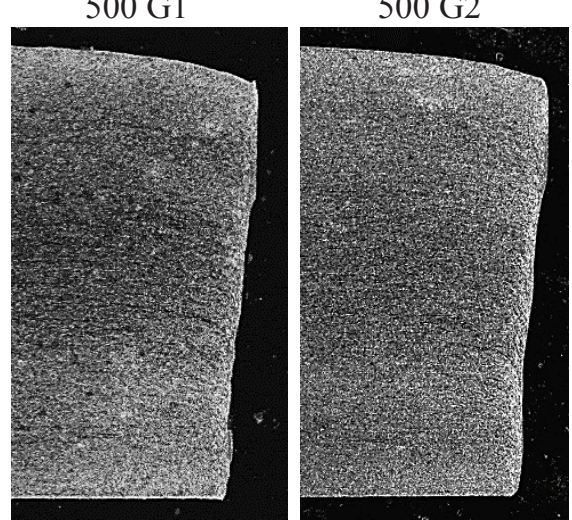

$1000 \mu \mathrm{m}$

Fig. 5. Cross-section of trimmed edges observed by optical microscopy. (a) 350 steel grade, and (b) 500 steel grade. Deformed microstructure can be observed in the cut edge.

Mechanical properties of the studied materials were evaluated by means of tensile tests using specimens extracted perpendicularly to the rolling direction. The UTS, YS and the total elongation (TE) of each material were evaluated using tensile test under monotonic loading conditions in a universal testing machine (not standardized specimen). The applied load rate was $2.5 \mathrm{~mm} / \mathrm{min}$.

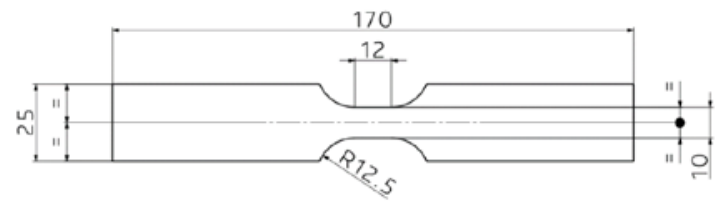

Fig. 6. Trimmed specimen geometry and dimensions.

Fatigue tests were conducted in a servo-hydraulic testing machine at four-point alternative bending $(\mathrm{R}=-1)$ at room temperature. This test configuration is selected because bending is the most common stress state in HDV parts. The fatigue limit ( $\sigma^{\mathrm{FAT}}-$ stress amplitude) was evaluated at $1 \times 10^{5}$, as it is the range used in the design process. At least 15 specimens for each material and condition were 
tested at a frequency of $10 \mathrm{~Hz}$. The maximum stress on the specimen was calculated using the four-point bending equation (1). Fracture surfaces were inspected by means of field emission scanning electron microscopy (FE-SEM).

$$
\sigma_{f}=\frac{3}{2} \cdot F_{a} \cdot \frac{\left(I_{1}-I_{2}\right)}{b \cdot h^{2}}
$$

Table 2 summarizes tensile test under monotonic loading and bending test under cyclic loading performed with the 350 and 500 steel specimens and different edge quality.

Table 2. Mechanical tests (monotonic (M) and cyclic (C)) for the two sheet steels and edge quality (G1 and G2).

\begin{tabular}{|c|c|c|c|c|}
\hline Edge & \multicolumn{2}{|c|}{ G1 } & \multicolumn{2}{c|}{ G2 } \\
\hline Test & M & C & M & C \\
\hline 350 & $\sqrt{ }$ & $\sqrt{ }$ & - & $\sqrt{ }$ \\
\hline 500 & $\sqrt{ }$ & $\sqrt{ }$ & - & $\sqrt{ }$ \\
\hline
\end{tabular}

\section{Results}

Monotonic and cyclic test results are summarized in Table 3 for all the tested materials and edge conditions employed.

Table 3. Values of yield stress (YS), ultimate tensile strength (UTS), total elongation at $10 \mathrm{~mm}$ (TE) and fatigue limit $\left(\sigma^{\mathrm{FAT}}\right.$ stress amplitude) for the studied steels.

\begin{tabular}{|c|c|c|c|c|}
\hline Material & $\begin{array}{c}\text { YS } \\
(\mathrm{MPa})\end{array}$ & $\begin{array}{c}\mathbf{U T S} \\
(\mathrm{MPa})\end{array}$ & $\begin{array}{c}\mathbf{T E}_{\mathbf{1 0 m m}} \\
(\%)\end{array}$ & $\begin{array}{c}\boldsymbol{\sigma}^{\text {FAT }} \\
(\mathrm{MPa})\end{array}$ \\
\hline $350-G 1$ & 464 & 477 & 58.4 & $362 \pm 17$ \\
\hline $350-G 2$ & - & - & - & $365 \pm 18$ \\
\hline $500-G 1$ & 641 & 651 & 43.3 & $421 \pm 21$ \\
\hline $500-G 2$ & - & - & - & $465 \pm 29$ \\
\hline
\end{tabular}

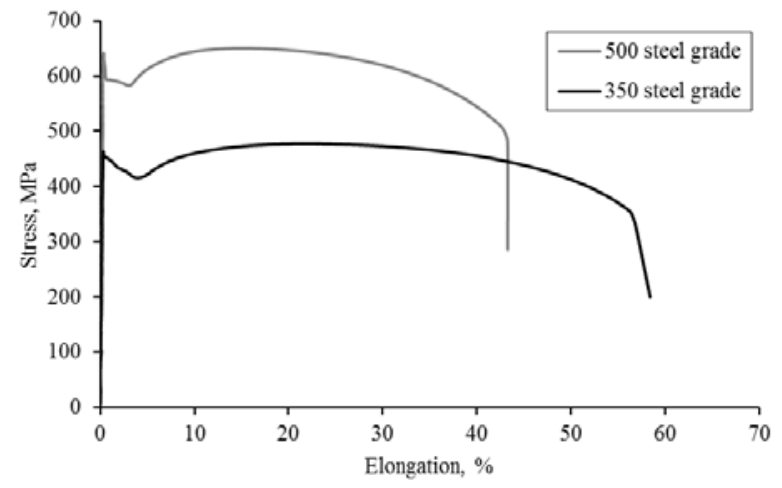

Fig. 7. Tensile test curves for the studied steels.

As observed in Fig.7, if the UTS increases the elongation decreases due to the differences observed in the microstructure. A fine microstructure can reach high strength but is not possible to maintain the elongation of the material.

Sandblasting process introduces compressive stresses on the surface. The residual stresses results from X-ray tensometry measurement of each steel grade are shown in Fig. 8.

Table 4. Compressive residual stresses measured in the surface for the studied steels.

\begin{tabular}{|c|c|}
\hline Material & $\boldsymbol{\sigma}_{\mathbf{c}}(\mathrm{MPa})$ \\
\hline $350-\mathrm{G} 2$ & $-339,7 \pm 27.5$ \\
\hline $500-\mathrm{G} 2$ & $-348.4 \pm 15.6$ \\
\hline
\end{tabular}

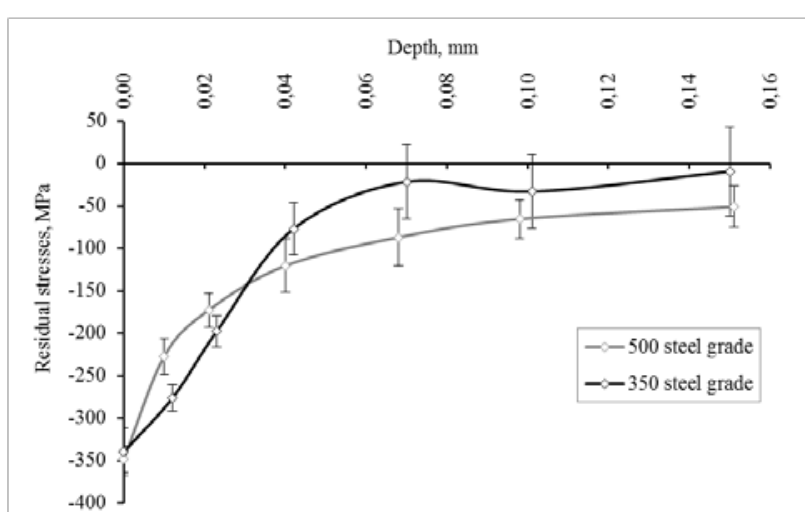

Fig. 8. Residual compressive stresses in the blasted surface for the studied steels.

As can be seen in Fig. 9(a)(b) fatigue strength is highly improved at high number of cycles for both materials because the crack nucleation is delayed by the compressive residual stresses of the sandblasting process.

a

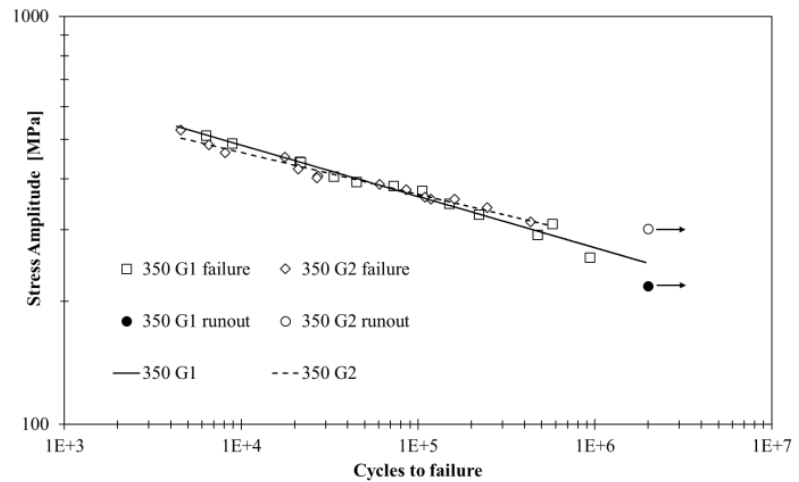

b

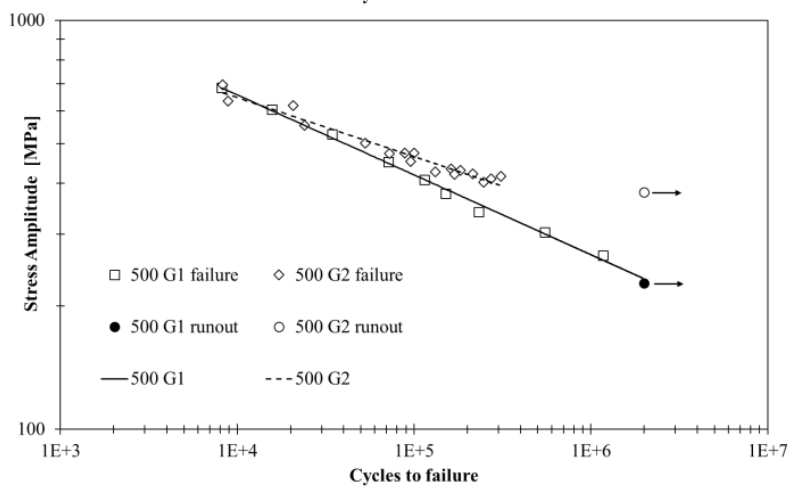

Fig. 9. Fatigue test curves for the studied steels. (a) 350 steel grade (b) 500 steel grade. 
Surface roughness is measured close to the upper and lower surface for each edge condition and material by an optical non-contact 3D microscope. Table 5 summarizes the $\mathrm{Rz}$ values in the smooth zone and in the fracture zone for the studied conditions.

Table 5. Surface roughness values (Rz) in the smooth zone and fracture zone for the studied materials.

\begin{tabular}{|c|c|c|c|c|}
\hline $\mathbf{R z}(\mu \mathrm{m})$ & 350-G1 & 350-G2 & 500-G1 & 500-G2 \\
\hline Smooth & $6 \pm 1$ & $5 \pm 1$ & $7 \pm 1$ & $5 \pm 1$ \\
\hline Fracture & $40 \pm 1$ & $7 \pm 1$ & $40 \pm 1$ & $14 \pm 2$ \\
\hline
\end{tabular}

\section{Discussion}

Although all the edges present the characteristics regions generated at the cut edge by mechanical cutting, different characteristics were observed depending on the strategy used. As can be seen in Fig. 5 G1 specimens have an irregular surface, sharp corners and also small burr. On contrary, in G2 specimens the surface is smooth without sharp areas, the corners are rounded and the burr is folded. The rollover region is similar for the two materials. The smooth zone is shorter as the strength of the material increase, due to a decrease in elongation of the material (Fig. 7). The fracture angle is bigger as the strength of the material decreases, because of the material elongation capacity increases.

Tensile residual stresses can be detrimental since it is equivalent to apply a tensile mean stress on the component that reduce the necessary applied stress for the crack initiation/crack growth. On contrary, when residual compressive stresses are present, the applied stress necessary to crack initiation/growth must be higher to negate the residual compressive stresses. Thus, residual compressive stresses on the surface are beneficial to increase the fatigue life. Although, focusing on 350 steel grade, there is no difference between fatigue strength of each edge condition at $1 \times 10^{5}$ cycles. In this case the surface smoothening and the compressive residual stresses are not beneficial to increase fatigue strength at the analysed number of cycles. In contrast, 500 steel grade shows a noticeable increment in fatigue strength on G2 edge condition at $1 \times 10^{5}$ cycles. Compressive residual stresses and changes on edge shape geometry are beneficial to increase the fatigue performance of this steel grade. The difference observed between G1 conditions can explained by grain size, i.e. the finer the microstructure is (more grain boundaries) the higher energy for crack propagation is needed (cycles required). This means that the higher steel grade has more resistance to crack propagation, i.e. higher damage resistance capacity [9]. On the other hand, sandblasting process has no effect on fatigue strength at low cycle fatigue regime because the residual stresses are easily cancelled by the high stresses in this regime.

Fatigue origins are related to surface irregularities and load ratio (R). Fig. 10 shows a typical fracture observed after the fatigue test. Multiple fatigue initiation sites (arrows in Fig. 10) are identified by FE-SEM. Alternative bending localizes the maximum stresses at the upper and lower surface of the specimen. It should be noted that in the centre of the specimen the applied stress is null. For this reason, the multiple crack origins are localized close to the surfaces, where stress is higher and not on the centre of the edge as might occur in tensile tests. It is in agreement with results from previous works [4]. FE-SEM images show multiple crack initiation sites. The cracks with small striations length are related to low stresses, which means that were the first cracks to nucleate and grew at low stresses until the stresses on the specimen were high enough to nucleate and propagate secondary cracks. On the other side, the cracks with wide striations are related to high stress, which means that the crack underwent a fast growth.

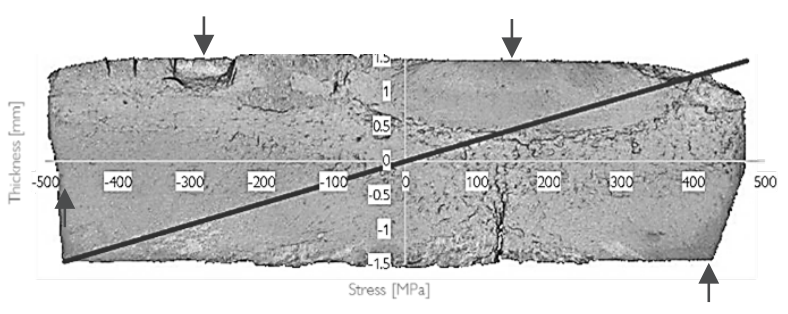

Fig. 10. Fracture and bending stress distribution of failed specimen.

Sandblasting introduces compressive residual stresses in the surface and also plastically deforms the edge reducing the surface roughness, folding the burr and smoothening the surface which decreases the notch effect $\left(\mathrm{K}_{\mathrm{t}}\right)$. Moreover, blasting operation removes the oxide scale observed in the studied specimens.

The fracture of each specimen was studied to determine the initial crack zone, see Fig 11-14. In G1 specimens crack initiation zone was mainly located in the fracture zone, because of the roughness and also the burr (stress concentrator) in this zone is highly stressed. Nevertheless, in G2 specimens the crack initiation zone is often observed in both zones, in the smooth zone and also in the fracture zone respectively.

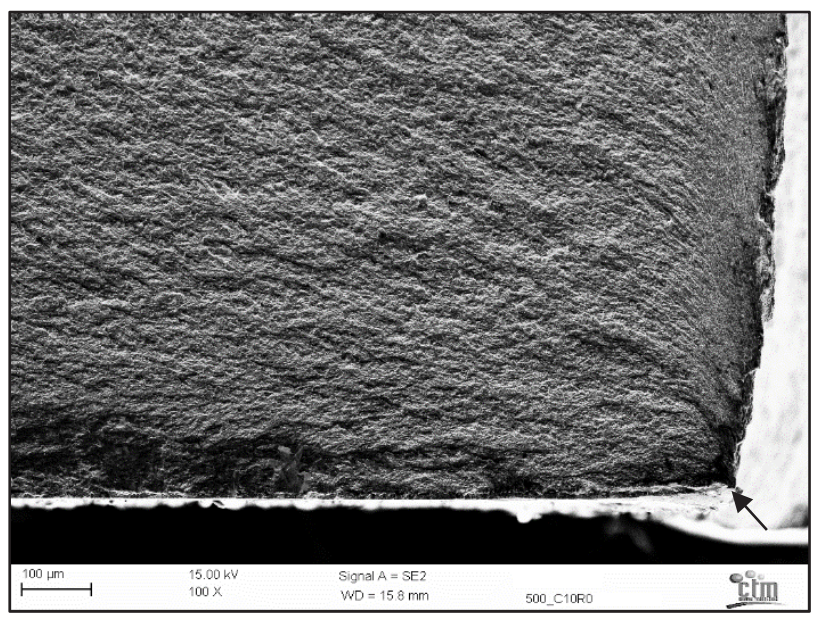

Fig. 11. Fractography of failed 350 steel grade specimen. Crack initiation in the burr of G1 specimen. 


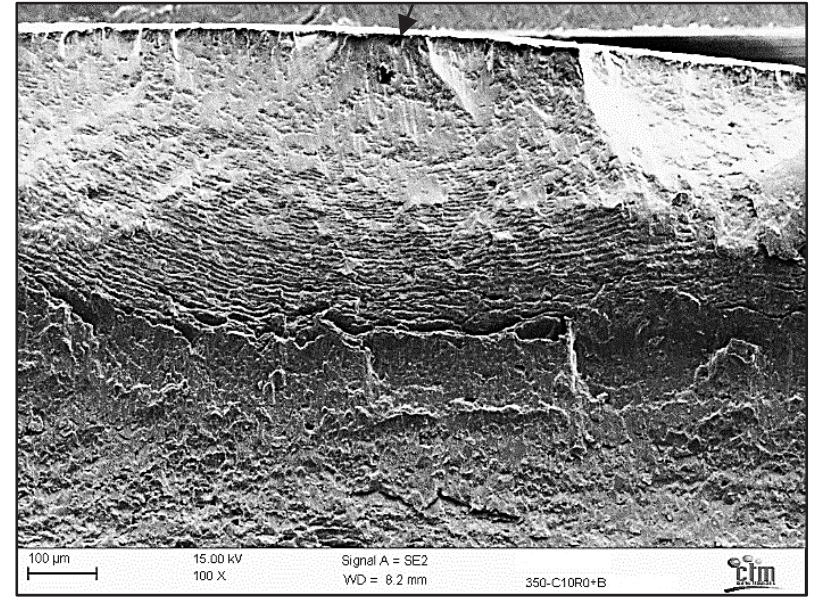

Fig. 12. Fractography of failed 350 steel grade specimen. Crack initiation in the surface of G2 specimen

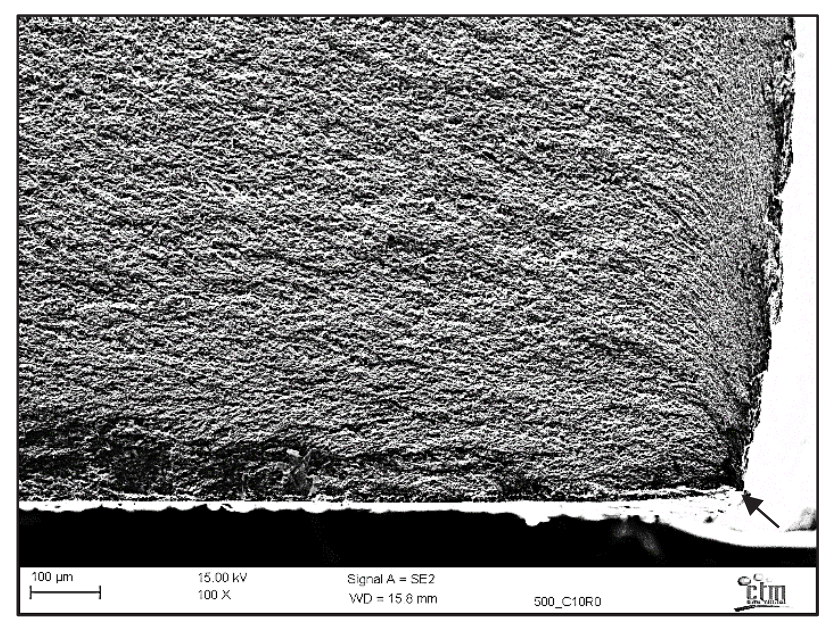

Fig. 13. Fractography of failed 500 steel grade specimen. Crack initiation in the burr of G1 specimen

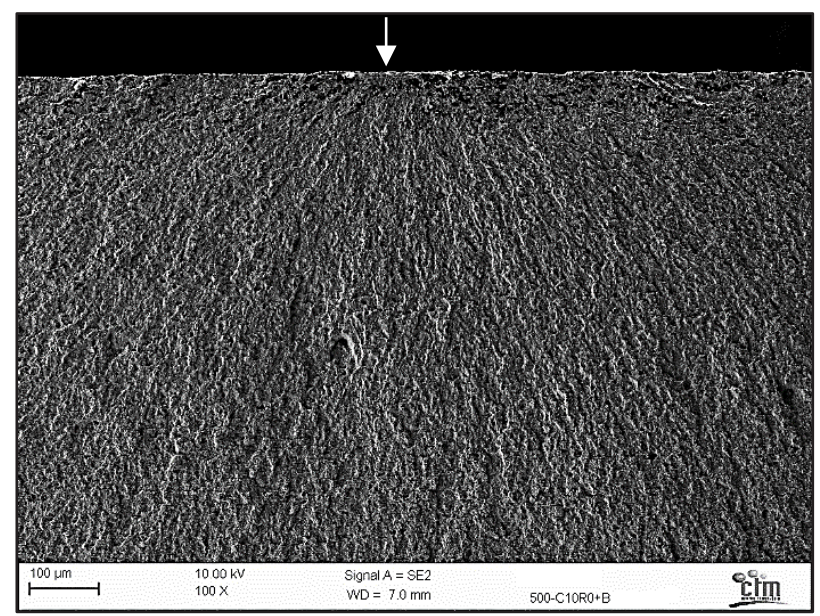

Fig. 14. Fractography of failed 500 steel grade specimen. Crack initiation in the surface of G2 specimen

\section{Conclusions}

The conclusions of this study based on the experimental tests, fractography analysis and shearing theory mentioned above are given below:

- Steel microstructure affects the characteristics of the sheared edge. A high strength steel shows small rollover area and smooth zone due to a low elongation of the material.

- Sandblasting process rounds the trimmed edges, folds the burr on the material and reduces the edge roughness. It also introduces compressive residual stresses that increase the fatigue performance.

- At low cycles the sandblasting has no effect on fatigue strength. On contrary, at high cycles (low stresses) the sandblasting increases the fatigue life.

- Bending tests generate the maximum stresses in the top and bottom surfaces of the specimen, whereas stress is null at specimen centre. For that reason, the crack nucleation tends to be localized in higher stresses areas (upper or lower surface). It implies that defects at surface (rollover and burr) dominates fatigue behaviour, whereas defects located at the edge fracture surface have a minimum impact on fatigue life.

\section{References}

[1] Study by CE Delft, "Marginal Abatement Cost Curves for HDVs", 2012 - http://eur-lex.europa.eu/legalcontent/EN/TXT/PDF/?uri=CELEX:52014DC0285\&fro $\underline{\mathrm{m}=\mathrm{EN}}$

[2] E. Maronne, A. Galtier, J.I. Robert, T. Ishikawa, Trans. Eng. Sci. 40 (2003)

[3] M. Kinefuchi, T. Kitamura; J. Soc. Mater. Sci., Japan, Vol.62, No.12, pp.764-769, (2013)

[4] A. Lara, I. Picas, D. Casellas, J. Mater. Process. Technol. 213 (2013)

[5] T. Stenberg, E. Lindgren, Z. Barsoum, I. Barmicho; Materialwissenschaft und Werkstofftechnik 48(6):556-569 (2017)

[6] D. Arola, A. E. Alade, W. Weber; Macch. Sci. tech. 10:197:218 (2006)

[7] H. Fujimoto, H. Ueda, R. Ueji, H. Fuji; ISIJ Inter. Vol 56, No. 7, pp. 1276-1284 (2016)

[8] K. Kolaøík, N. Ganev, Z. Pala, J. Drahokoupil; Mat. Struct., Vol. 22, No. 2 (2015)

[9] H. SuzukiA. J. Mcevily ; Met. Trans. Volume 10, Issue 4, pp 475-481 (1979) 